\title{
Redescription of Eimeria dorcadis Mantovani, 1966 (Apicomplexa: Eimeriidae) from the dorcas gazelle (Gazella dorcas) in Saudi Arabia
}

\author{
Osama B. Mohammed ${ }^{1}$, Abdulaziz N. Alagaili ${ }^{1}$ and Sawsan A. Omer ${ }^{2}$ \\ ${ }^{1}$ KSU Mammals Research Chair, Department of Zoology, College of Science, King Saud University, P. O. Box 2455, Riyadh \\ 11451, Saudi Arabia; \\ ${ }^{2}$ Department of Zoology, College of Science, King Saud University, University Centre for Women Students, P. O. Box 22452, \\ Riyadh 11495, Saudi Arabia
}

\begin{abstract}
Eimeria dorcadis Mantovani, 1966 is redescribed from dorcas gazelle (Gazella dorcas (L.)) from Saudi Arabia. Oocysts were detected in 7 out of 22 faecal samples (32\%) using floatation method. The sporulated oocysts are cylindrical, slightly flattened at the micropylar pole, measure in average $32 \times 19 \mu \mathrm{m}(27-36 \times 16-24 \mu \mathrm{m})$, length/width ratio being 1.7 (1.5-2.1). Oocyst wall is $1.2 \mu \mathrm{m}$ thick, smooth, double-layered; outer layer is slightly thicker, light blue in colour; inner layer brownish, with micropyle in the inner layer and apparently continual outer one, measures $2.2 \mu \mathrm{m}$, but lacks a micropylar cap. The sporocyst elongateellipsoidal, measures $14 \times 8 \mu \mathrm{m}(12-17 \times 6-9 \mu \mathrm{m})$, length/width ratio being 1.8, with sporocyst residuum as circular compact, coarse, refractile granules. Stieda body is present, while substieda body is absent. Sporozoites banana-shaped, measure $11 \times 2.5 \mu \mathrm{m}$, each with a large spheroidal refractile body at the wider pole. Sporulation time is $2-3$ days at $25 \pm 2{ }^{\circ} \mathrm{C}$.
\end{abstract}

Keywords: coccidia, Gazella dorcas, Saudi Arabia, Eimeria dorcadis, morphology

Dorcas gazelle, Gazella dorcas (Linnaeus, 1758), is widely distributed in northern Africa from Morocco to Egypt, extending eastwards into Jordan and south Negev including the Yotvata region of Arava Valley (Anonymous 1946, Baharav 1982, Harrison and Bates 1991, Yom-Tov et al. 1995) and southwards to northern Sudan, Ethiopia and Somalia.

Gazella dorcas is polytypic and currently comprises five subspecies: G. dorcas pelzelni in the Somalian region, G. dorcas dorcas in the Western Desert of Egypt, G. dorcas isabella (syn. G. d. littoralis) in the Eastern Desert and the hills of the Red Sea, Sinai and southern Israel, G. dorcas massaesyla on the Moroccan high plateaux and in the Atlantic Sahara and its fringes, and G. dorcas osiris (syn. G. d. neglecta) in the Sahel, the central Saharan massifs and the northern fringes of the western Sahara (Groves 1969, 1988, Osborn and Helmy 1980, Alados 1986). The Saudi gazelle was once classified as a subspecies of dorcas gazelle, G. dorcas saudiya, but later it has been classified as a distinct species and later investigations have shown that the Saudi gazelle is extinct (Ellerman and Morrison-Scott 1951, Groves 1988, Rebholz et al. 1991, Hammond et al. 2001).

Apart from the Saudi gazelle (G. saudiya), antelopes indigenous to Saudi Arabia include the Arabian oryx
(Oryx leucoryx), sand gazelle (Gazella subgutturosa marica) and the mountain gazelle (Gazella gazella). Both G. s. marica and G. gazella were reintroduced from a captive stock held at the King Khalid Wildlife Research Centre of the Saudi Wildlife Authority into two protected areas in the Kingdom, i.e. Mahazat As Sayd and Uruq Bani Ma-Arid (Haque and Smith 1996, Wacher and Kichenside 1998), and Ibex Reserve and Uruq Bani Ma-Arid (Dunham 1995, 1997, Dunham et al. 1993).

Eimeria infections are common in both domestic and wild artiodactyls in Saudi Arabia (Kasim et al. 1985, 1991, Ghandour 1988, Kasim and Al-Shawa 1988, Alyousif et al. 1992, Mohammed 1997, Toula 2007). Omer at al. (2011) reviewed the eimerian parasites of the genus $\mathrm{Ga}$ zella Blainville, 1816 and they added Eimeria farasanii Omer, Apio, Wronski et Mohammed 2011 from Farasan gazelle, G. gazella farasani, to the seven known species of Eimeria (Hussein and Mohammed 1992, Mohammed and Hussein 1992). Only one species of Eimeria has been described from the dorcas gazelle and was not found to be infectious to sheep and goats (Levine and Ivens 1986).

The diseases and parasites of the dorcas gazelle have rarely been described. The prevalence of gastrointestinal parasites of gazelles including dorcas gazelles in Saudi Arabia has been reviewed by Mohammed (1997). Evi- 
dence of cyst-forming coccidian was first documented from dorcas gazelle in Saudi Arabia by Mohammed and Hussein (1994) and Mohammed et al. (2000).

This study aimed to redescribe a coccidian species, Eimeria dorcadis, which was inadequately described previously by Mantovani (1966), and to compare it with other eimerian species detected in other members of the genus Gazella.

\section{MATERIAL AND METHODS}

Dorcas gazelles (Gazella dorcas) used in the present study were descendants of a group of gazelles brought from the Sudan during the 1970s and bred at the King Khalid Wildlife Research Centre since then. Dorcas gazelles were housed in breeding pens measuring $100 \times 50 \mathrm{~m}$ and each pen holds 10 breeding females with a single male (Kichenside and Lindsay 1997). Fresh faecal samples were collected into screw-capped, wide mouth plastic containers directly from the rectum of each of 22 gazelles. In the laboratory, faecal samples were subjected to parasitological examinations including direct smear, sedimentation and floatation using saturated sodium chloride $(\mathrm{NaCl})$ solution. Parasitic burden for each animal was assessed using the modified McMaster technique (Anonymous 1986). Faecal samples showing coccidian oocysts were cultured for sporulation at room temperature $\left(25 \pm 2{ }^{\circ} \mathrm{C}\right)$ in a shallow aqueous layer of $2.5 \%$ potassium dichromate $\left(\mathrm{K}_{2} \mathrm{Cr}_{2} \mathrm{O}_{7}\right)$ as described by Mohammed and Hussein (1992). The faecal cultures were examined daily for demonstration of sporulated oocysts and the time for sporulation was recorded.

Measurements were made using calibrated ocular micrometre and photographs were taken using a Nikon camera attached to a Nikon microscope (Nikon Company, Japan). All measurements are given in micrometres $(\mu \mathrm{m})$ as means followed by range in parentheses. The morphology and morphometry of oocysts described in the present study were compared with those reported from members of the genus Gazella.

\section{RESULTS}

Seven out of 22 sampled dorcas gazelles (32\%) were infected with a single species of Eimeria. The number of oocysts per gram of faeces (OPG) ranged between 1500 and 9500 OPG. The Eimeria species observed in the present study is different from those found in other gazelles at the King Khalid Wildlife Centre and appeared morphologically indistinguishable from Eimeria dorcadis, which was described by Mantovani (1966) (Table 1). This species is thus redescribed here.

\section{Redescription: Eimeria dorcadis Mantovani, 1966} Fig. 1A, B

Description of unsporulated and sporulated oocysts: unsporulated oocysts cylindrical, slightly flattened at micropylar pole. Oocyst wall $1.2(1.0-1.5)$ thick, smooth, double-layered. Outer layer slightly thicker, light blue in colour, inner layer brownish, with narrow micropyle in inner layer and outer layer apparently continual, measuring 2.2 (1.5-3.0), but without micropylar cap. Sporulated oocysts $(n=100) 32 \times 19(27-36 \times 16-24)$, mean length/ width ratio $1.7(1.5-2.1)$. Oocyst residuum and oocyst polar granules both absent.

Description of sporozoites: each sporulated oocyst with four elongate-ellipsoidal sporozoites, measuring 14 $\times 8(12-17 \times 6-9)(\mathrm{n}=150)$, and mean length/width ratio 1.8 (1.4-2.3). Stieda body present, but substieda body absent. Sporocyst residuum consists of circular compact, coarse, refractile granules. Sporozoites banana-shaped $(\mathrm{n}=50)$, measuring $11 \times 2.5(9-12 \times 2-3)$, each with spheroidal to ellipsoidal small refractile bodies at wider pole.

Table 1. Comparison of Eimeria dorcadis (this study and original description - Mantovani, 1966) and other Eimeria species described from members of the genus Gazella.

\begin{tabular}{|c|c|c|c|c|c|c|c|}
\hline \multirow[t]{2}{*}{ Eimeria species } & $\begin{array}{l}\text { Mean size } \\
\text { (range) }\end{array}$ & $\begin{array}{l}\text { Micro- } \\
\text { pyle }\end{array}$ & $\begin{array}{l}\text { Micro- } \\
\text { pylar cap }\end{array}$ & $\begin{array}{l}\text { Polar } \\
\text { granule }\end{array}$ & $\begin{array}{c}\text { Stieda } \\
\text { body }\end{array}$ & $\begin{array}{l}\text { Resi- } \\
\text { duum }\end{array}$ & \multirow[t]{2}{*}{ Type host } \\
\hline & \multicolumn{4}{|c|}{ Oocyst } & \multicolumn{2}{|c|}{ Sporocyst } & \\
\hline Eimeria dorcadis Mantovani, 1966 & $\begin{aligned} 29 & \times 18 \\
(26-31 & \times 15-26)\end{aligned}$ & - & - & - & - & + & dorcas gazelle, Gazella dorcas \\
\hline $\begin{array}{l}\text { E. dorcadis } \\
\text { (Redescription, this study) }\end{array}$ & $\begin{aligned} 32 & \times 19 \\
(27-36 & \times 16-24)\end{aligned}$ & + & - & - & + & + & dorcas gazelle, Gazella dorcas \\
\hline $\begin{array}{l}\text { E. farasanii Omer, Apio, Wronski et } \\
\text { Mohammed, } 2011\end{array}$ & $\begin{aligned} 21 & \times 20 \\
(19-25 & \times 18-25)\end{aligned}$ & + & - & - & + & + & Farasan gazelle, Gazella gazella farasani \\
\hline E. idmii Mohammed et Hussein, 1992 & $\begin{aligned} 42 & \times 30 \\
(36-48 & \times 27-37)\end{aligned}$ & + & + & - & + & + & Arabian mountain gazelle, Gazella gazella \\
\hline $\begin{array}{l}\text { E. rheemi Hussein et Mohammed, } \\
1992\end{array}$ & $\begin{aligned} 25 & \times 21 \\
(20-34 & \times 18-30)\end{aligned}$ & + & - & - & + & + & $\begin{array}{c}\text { Arabian sand gazelle, } \\
\text { Gazella subgutturosa marica }\end{array}$ \\
\hline E. abenovi Svanbaev, 1979 & $\begin{aligned} 32 & \times 23 \\
(23-41 & \times 19-26)\end{aligned}$ & + & - & - & - & + & goitred gazelle, Gazella subgutturosa \\
\hline E. gazella Musaev, 1970 & $\begin{aligned} 24 & \times 20 \\
(20-28 & \times 17-25)\end{aligned}$ & - & - & - & - & + & goitred gazelle, Gazella subgutturosa \\
\hline $\begin{array}{l}\text { E. chinkari Pande, Bhatia, Chauhan et } \\
\text { Grag, } 1970\end{array}$ & $\begin{aligned} 25 & \times 22 \\
(24-27 & \times 19-26)\end{aligned}$ & - & - & - & + & + & gazelle or chinkara, Gazella gazella \\
\hline $\begin{array}{l}\text { E. elegans Yakimoff, Gousseff et } \\
\text { Rastegaieff, } 1932\end{array}$ & $(23-45 \times 16-25)$ & + & - & \pm & - & + & goitred gazelle, Gazella subgutturosa \\
\hline
\end{tabular}

\pm from the original description: oocyst with or without polar granule. 

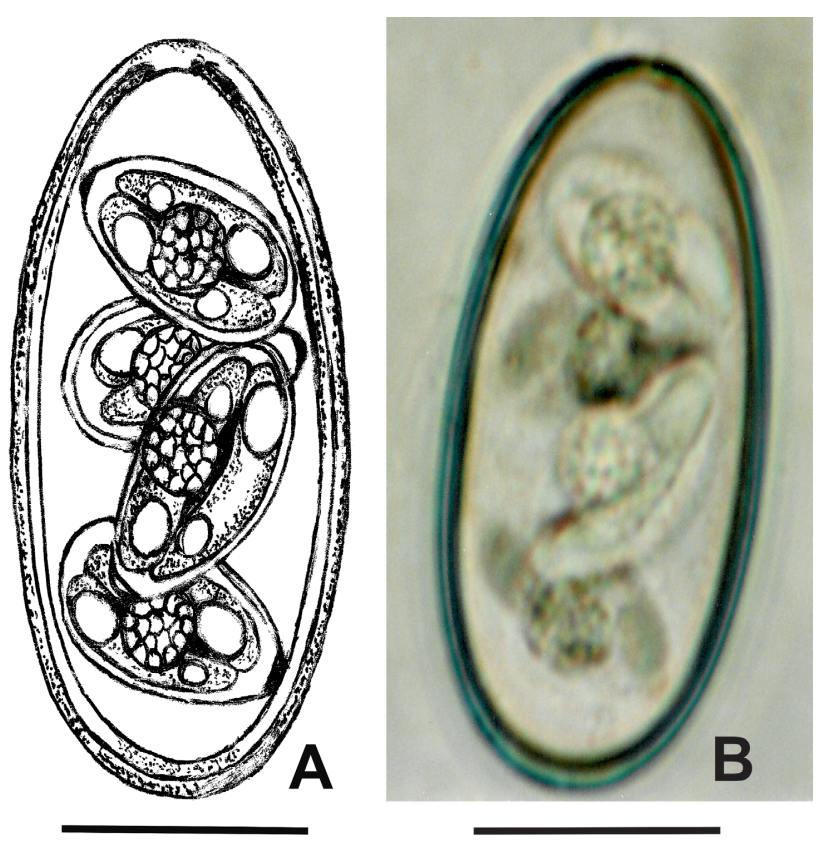

Fig. 1. A composite line drawing (A) and a photomicrograph (B) of sporulated oocyst of Eimeria dorcadis from the faeces of dorcas gazelle (Gazella dorcas) kept at the King Khalid Wildlife Research Centre, Thumamah. Scale bar $=10 \mu \mathrm{m}$.

Type host: Dorcas gazelle, Gazella dorcas (Linnaeus, 1758).

Distribution: North Africa (type locality), Sudan, Thumamah, King Khalid Wildlife Research Centre, Saudi Arabia.

Prevalence: In 7 out of $22(32 \%)$ dorcas gazelles at the King Khalid Wildlife Research Centre.

Infection rate: Low-level infection (1500-9500 oocyst/ gram of faeces) was found in infected gazelles.

Site of infection: Unknown, oocysts recovered from faeces.

S porulation: Exogenous, within $2-3$ days at $25 \pm 2{ }^{\circ} \mathrm{C}$ in $2.5 \% \mathrm{~K}_{2} \mathrm{Cr}_{2} \mathrm{O}_{7}$

Types: Photoneosyntype (see Duszynski 1999 for terminology) deposited at the Museum of the Department of Zoology, College of Science, King Saud University (Acc. No. 705).

Remarks: Oocysts detected in the present study are considered to be conspecific with Eimeria dorcadis Mantovani, 1966 because of their morphological similarity. However, there was slight difference in the measurements of the sporozoites, the presence of a micropyle in the inner layer of the oocysts and the presence of stieda body. These features have not been described previously by Mantovani (1966). The oocyst measurements from the present study overlap with those given by Mantovani (1966) in his original description of E. dorcadis.

The oocysts of $E$. dorcadis are different morphologically and morphometrically from those of both Eimeria idmii Mohammed et Hussein, 1992 and Eimeria rheemi Hussein et Mohammed, 1992, which have been reported previously from Gazella gazella and Gazella subgutturosa marica, respectively. Therefore, E. dorcadis is distinguished from other eimerian parasites infecting members of the genus Gazella in the shape and size of its oocysts. This coccidian parasite is probably of low pathogenicity.

\section{DISCUSSION}

To date, 8 species of Eimeria have been described from the members of the genus Gazella and have recently been reviewed by Omer et al. (2011). Only one species of Eimeria was described from dorcas gazelle and was named Eimeria dorcadis (see Levine and Ivens 1986). It is interesting to find this coccidian parasite in this host kept at the King Khalid Wildlife Research Centre, Thumamah, which was said to be brought from the Sudan. Since other members of Gazella living under the same conditions are infected with other species of Eimeria and not with E. dorcadis, we believe this parasite from dorcas gazelle is specific to this host.

The oocysts described during this study exhibited sizes that overlap those of E. dorcadis, however, additional features that were not described previously by Mantovani (1966) are demonstrated. Eimeria dorcadis shows considerable variation in the dimensions of the oocysts. Interestingly, such variation was also noticed in other coccidian parasites infecting other members of the genus Gazella (Table 1).

Of the additional features worth mentioning is the presence of a micropyle which was claimed to be absent by Mantovani (1966), the presence of a double-layered wall as well as the presence of a stieda body. It is interesting that the micropyle shown in the oocysts in the present study was only visible in the inner layer of the oocysts, whereas the outer layer apparently looked continual. The micropyle of such an unusual appearance may have been overlooked in the original description. It was unclear whether the stieda body was not recognized in the original description as it was clearly visible in this study.

It appears that all eimerian parasites described from members of the genus Gazella lack oocyst residuum and polar granules, although oocysts of E. elegans Yakimoff, Gousseff et Rastegaieff, 1932 from G. gazella were described either having polar granules or not (Mantovani 1966, Pellérdy 1974, Levine and Ivens 1986). They all possess a sporocyst residuum (Svanbaev 1979, Levine and Ivens 1986).

Eimeria chinkari Pande, Bhatia, Chauhan et Grag, 1970 was described from the host identified as G. gazella, but reported as chinkara. Since chinkara is the Indian gazelle (Gazella bennetti), not G. gazella, the type host of E. chinkari needs to be revised and E. chinkari should be provisionally considered as a parasite of $G$. bennetti. Kasim et al. (1991) redescribed E. gazella and found out that the oocysts of E. gazella contained numerous small polar granules and a sporocyst residuum. It is possible 
that one of the sporocysts may have ruptured, thus releasing the granules forming the sporocyst residuum; such granules appear as if they were of oocystic rather than sporocystic origin. Furthermore, the original description of E. gazella was from the goitred gazelle (Gazella subgutturosa) and its finding in Gazella gazella arabica would raise a question of whether E. gazella can infect both G. gazella as well as G. subgutturosa. Wronski et al. (2010) reviewed the taxonomy of G. gazella in the Arabian Peninsula including gazelles from Farasan Islands. Farasan gazelle is distinguishable from both mainland populations and the type specimen of G. arabica, putatively collected at Farasan in the 19th century (Groves 1983, Thouless and Al-Bassri 1991). It remains unknown if Kasim et al. (1991) have really examined specimens of G. gazella arabica or another species of Gazella.

Ruiz de Ybáñez et al. (2001) have reported Eimeria gazella and E. pallida from the mohor gazelle, Gazella dama mhorr, Cuvier's gazelle, G. cuvieri, and dorcas gazelle, G. dorcas neglecta, kept in captivity in Spain. Furthermore, they have also shown that both G. cuvieri and G. dorcas neglecta shed oocysts of Eimeria elegans. Both E. elegans and E. gazella were originally described from the goitered gazelle, G. subgutturosa. Reports of these coccidian parasites from a different host also raise a ques- tion whether they are species-specific or not (Levine and Ivens 1986).

Eimeria pallida Christensen, 1938 was described from both goats and sheep, but Levine and Ivens (1986) questioned the species described from sheep and considered it as a new species typical of sheep and goat. Ruiz de Ybáñez et al. (2001) did not specify which one they had detected. Cross transmission experiments with both E. elegans and E. gazella to infect sheep and goat were unsuccessful (Yakimoff et al. 1932, Svanbaev 1979). With the strict host specificity of Eimeria species, it remains unclear whether species reported from gazelles in Spain are new species or species described before that occur in different hosts.

The finding of E. dorcadis exclusively in dorcas gazelle, which lives under the same conditions as the mountain gazelle, G. gazella, sand gazelle, G. subgutturosa marica, as well as the Arabian oryx, Oryx leucoryx, suggests that this species parasitizes only dorcas gazelle and not any other antelope at the King Khalid Wildlife Research Centre.

Acknowledgements. The authors extend their appreciation to the Deanship of Scientific Research at the King Saud University for funding the work through the research group project No. RGP-VPP-020.

\section{REFERENCES}

Alados C.L. 1986: The use of tail and rump patch in the dorcas gazelle (Gazella dorcas L.). Mammalia 50: 439-446.

Alyousif M.S., Kasim A.A., Al-Shawa Y.R. 1992: Coccidia of the domestic goat (Capra hircus) in Saudi Arabia. Int. J. Parasitol. 22: 807-811.

AnONymous 1946: The Schmitz collection of mammals. Bulletin Jerusalem Nat. Club. 23: 1-2.

AnONymous 1986: Manual of Veterinary Parasitological Laboratory Techniques. Technical Bulletin, No. 18, Ministry of Agriculture, Forestry and Fisheries, Great Britain. Her Majesty's Stationary Office, London, England, 118 pp.

BaharaV D. 1982: Desert partitioning by dorcas gazelle. J. Arid Environ. 5: 323-335.

Dunham K.M. 1995: Gazelles, oryx and ostriches in Saudi Arabia. Re-Introduction News 11: 7-8.

Dunнaм K.M. 1997: Gazelles and oryx in Saudi Arabia. Re-Introduction News 13: 5-6.

Dunham K.M., Kichenside T.B., Lindsay N., Rierkerk F.E., Williamson D.T. 1993: The reintroduction of mountain gazelle, Gazella gazella, in Saudi Arabia. Int. Zoo Yearb. 32: 107-116.

DuszYNSKI D.W. 1999: Revisiting the code: clarifying namebearing type for photomicrographs of Protozoa. J. Parasitol. 85: $769-770$

Duszynski D.W., Wilber P.G. 1997: A guideline for the preparation of species description in the Eimeriidae. J. Parasitol. 83: 333-336.

Duszynski D.W., Upton S.J. 2001: Cyclospora, Eimeria, Isospora, and Cryptosporidium. In W.M. Samuel, M.J. Pybus and
A.A. Kocan (Eds.), Parasitic Diseases of Wild Mammals. Mason Publishing/The Veterinary Press, London, pp. 416-459.

Ellerman J.R., Morrison-Scott T.C.S. 1951: Checklist of Palearctic and Indian mammals, 1758 to 1946. Trustees of the British Museum, London, UK, 810 pp.

Ghandour A.M. 1988: Hazards to rangelands in Saudi Arabia: importance of diseases via livestock. Fauna Saudi Arabia 9: 468-477.

Groves C.P. 1969: On the smaller gazelles of the genus Gazella de Blainville, 1816. Z. Säugetierkd. 34: 38-60.

Groves C.P. 1983: Notes on the gazelles IV: the Arabian gazelles collected by Hemprich and Ehrenberg. Z. Säugetierkd. 48: 371-381.

Groves C.P. 1988: A catalogue of the genus Gazella. In A. Dixon and D. Jones (Eds.), Conservation and Biology of Desert Antelopes. Christopher Helm., London, pp. 193-198.

Hammond R.L., Macasero W., Flores B., Mohammed O.B., Wacher T., Bruford M.W. 2001: Phylogenetic re-analysis of the Saudi gazelle, Gazella saudiya and its implications for conservation. Conserv. Biol. 15: 1123-1133.

Haque M.N., Smith T.R. 1996: Reintroduction of Arabian sand gazelle Gazella subgutturosa marica in Saudi Arabia. Biol. Conserv. 76: 203-207.

Harrison D.L., Bates P.J.J. 1991: The Mammals of Arabia. 2nd Ed. Harrison Zoological Museum Publications. Seven Oaks, UK, 354 pp.

Hussein H.S., Mohammed O.B. 1992: Eimeria rheemi sp. n. (Apicomplexa: Eimeriidae) from Saudi Arabian sand gazelle, Gazella subgutturosa marica (Artiodactyla: Bovidae) in Saudi Arabia. J. Helminthol. Soc. Wash. 59: 190-194. 
Kasim A.A., Al-Shawa Y.R. 1988: Eimeria saudiensis n. sp. (Apicomplexa: Eimeriidae) from the Arabian oryx (Oryx leucoryx) in Saudi Arabia. J. Protozool. 35: 520-521.

Kasim A.A., Al-Yousif M.S., Al-Shawa Y.R. 1991: Redescription of Eimeria gazella Musaev, 1970 (Apicomplexa: Eimeriidae) from the Arabian gazelle, Gazella gazella arabica (Artiodactyla: Bovidae) in Saudi Arabia. Parassitologia 33: 107-109.

Kasim A.A., Hussein H.S., Al-Shawa Y.R. 1985: Coccidia in camels (Camelus dromedarius) in Saudi Arabia. J. Protozool. 32: 202-203.

Kichenside T.B., Lindsay N.B. 1997: The husbandry of gazelles at King Khalid Wildlife Research Centre. In: K. Habibi, A. Abu-Zinada and I. Nader (Eds.), The Gazelles of Arabia. National Commission for Wildlife Conservation and Development, Riyadh, Publication No. 29, pp. 219-230.

Levine N.D., Ivens V. 1986: The Coccidian Parasites (Protozoa, Apicomplexa) of Artiodactyls. Illinois Biological Monograph 55, University of Illinois Press, Urbana, Illinois, 285 pp.

Mantovani A. 1966: Eimeria dorcadis n. sp. (Protozoa: Eimeriidae) parasite di Gazella dorcas (L.). Parassitologia 8: 13-15.

Mohammed O.B. 1997: Parasites of Arabian gazelles. In: K. Habibi, A. Abu-Zinada and I. Nader (Eds.), The Gazelles of Arabia. National Commission for Wildlife Conservation and Development, Riyadh, Saudi Arabia, pp. 192-207.

Mohammed O.B., Hussein H.S. 1992: Eimeria idmii sp. n. (Apicomplexa: Eimeriidae) from the Arabian mountain gazelle, $G a$ zella gazella, in Saudi Arabia. J. Helminthol. Soc. Wash. 59: $120-124$.

Mohammed O.B., Hussein H.S. 1994: Antibody prevalence of toxoplasmosis in Arabian gazelles and oryx in Saudi Arabia. J. Wildl. Dis. 30: 560-562.

Mohammed O.B., Davies A.J., Hussein H.S., Daszak P. 2000: Sarcocystis infections in gazelles at the King Khalid Wildlife Research Center, Saudi Arabia. Vet. Rec. 146: 218-221.

Omer S.A., Apio A., Wronski T., Mohammed O.B. 2011: A new coccidian parasite (Eimeria farasanii n. sp.) indicates parasitehost specificity in endemic Farasan gazelle. Int. J. Zool. Res. 7: $85-92$.

Received 18 November 2011
Osborn D.J., Helmy I. 1980: The contemporary land mammals of Egypt (including Sinai). Fieldiana Zoology, new series 5: $1-579$.

Pellérdy L.P. 1974: Coccidia and Coccidiosis. 2nd Ed. Akad. Kiadó, Budapest and Paul Parey, West Berlin, 959 pp.

Rebholz W.E.R., Williamson D., Rietkerk F. 1991: Saudi gazelle (Gazella saudiya) is not a subspecies of dorcas gazelle. Zoo Biol. 10: 485-489.

Ruiz de Ybáñez M., Ortiz J.M., Garijo M.M., Espeso G., AbaiGar T., CAno M. 2001: Records of Eimeria spp. and their excretion in captive North African gazelles. Comp. Parasitol. 68: 134-137.

Svanbaev S.K. 1979: [Coccidia of Wild Animals in Kazakhstan] Izdat "Nauka", Kazakh. SSR, Alma-Ata. Kazakhstan. 212 pp. (In Russian.)

Toula F.H. 2007: Prevalence and comparative morphological studies of four Eimeria sp. of sheep in Jeddah area, Saudi Arabia. J. Biol. Sci. 7: 413-416.

Thouless C.R., Al-Bassri K. 1991: Taxonomic status of the Farasan Island gazelle. J. Zool. 223: 151-159.

WACher T.W., Kichenside T.B. 1998: Reintroducing the sand gazelle Gazella subgutturosa marica to Urug Bani Ma'arid Protected Area: empty quarter of Saudi Arabia. Re-Introduction News 15: 10-12.

Wronski T., Wacher T.J., Hammond R.L., Winney B., Hundertmark K., Blacket M.J., Mohammed O.B., Flores B., Omer S.A., Macasero W., Plath M., Tiedemann R., BleiDORN C. 2010: Two reciprocally monophyletic mtDNA lineages elucidate the taxonomic status of mountain gazelles (Gazella gazella). Syst. Biodiv. 8: 1-10.

Yakimoff W.L., Gousseff W.F., RastegaiefF E.F. 1932: Die Coocidiose der wilden kleinen Wiederkauer. Z. Parasitenkd. 5: 85-93.

Yom-Tov Y., Mendelssohn H., Groves C.P. 1995: Gazella dorcas. Mamm. Species 491: 1-6.

Accepted 26 January 2012 